\title{
Program Penerapan Teknologi Tepat Guna Implementasi ASTER (Alat Silase Terkompartemen) untuk Peternak Domba di Wilayah Kadudampit Kabupaten Sukabumi
}

\author{
Suhendar ${ }^{(1)^{*}}$, Billyardi Ramdhan ${ }^{(1)}$, Ade Sudarma ${ }^{(2)}$ \\ (1) Program Studi Pendidikan Biologi, FKIP, Universitas Muhammadiyah Sukabumi \\ ${ }^{(2)}$ Program Studi Akuntansi, Fak. Ekonomi, Universitas Muhammadiyah Sukabumi \\ *Surat ElektronikPenulis: suhendar@ummi.ac.id
}

\begin{abstract}
The application of Appropriate Technology to the Community was carried out in Kadudampit District, Sukabumi Regency, West Java Province. As the sub-district mapped to be one of the sheep breeding centers by the Sukabumi Regency government, the farmers have problems with the availability of fresh forage which is limited during the dry season. They also do not have the ability to make silage and design silage tools that are truly effective and efficient. The aim of this program is to provide information and skills to the sheep breeders group about silage feed technology, design and use of the Compartment Silage Tool (ASTER). The method used in this service consists of seven stages of activities, including: 1) Activity Socialization; 2) Design of the Compartment Silage Tool Implementation; 3) Assembling the Compartment Silage Tool; 4) Compartment Silage Tool Operation Test; 5) Operational Assistance and Completion of the Compartment Silage Tool; 6) Application and grant of Compartment Silage Tool; and 7) the monitoring and evaluation stage, aims to see the progress and achievements of each stage of the program so that all programs can be carried out according to the objectives. The results of dedication showed an increase in the ability to make silage using compartmental silage in the breeders.
\end{abstract}

Keyword: Silage, Compartment Silage Tool

\begin{abstract}
Abstrak
Penerapan Teknologi Tepat Guna Kepada Masyarakat ini dilakukan di Kecamatan Kadudampit, Kabupaten Sukabumi Provinsi Jawa Barat. Sebagai kecamatan yang dipetakan menjadi salah satu sentra peternak domba oleh pemerintah Kabupaten Sukabumi, para peternaknya memiliki masalah akan ketersediaan pakan hijauan segar yang terbatas pada saat musim kemarau. Mereka juga tidak memiliki kemampuan membuat silase serta merancang alat silase yang benar-benar efektif dan efisien. Tujuan dari program Penerapan Teknologi Tepat Guna Kepada Masyarakat ini adalah memberikan sosialisasi dan keterampilan kepada kelompok peternak domba tentang teknologi pakan silase, perancangan dan penggunaan Alat Silase Terkompartemen (ASTER). Metode yang digunakan dalam pengabdian ini terdiri atas tujuh tahap kegiatan, antara lain: 1) Sosialisasi Kegiatan; 2) Perancangan Implementasi Alat Silase Terkompartemen; 3) Perakitan Alat Silase Terkompartemen; 4) Uji Operasi Alat Silase Terkompartemen; 5) Pendampingan Operasional dan Penyempurnaan Alat Silase Terkompartemen; 6) Penerapan dan menghibahkan Alat Silase Terkompartemen; dan 7) tahap monitoring dan evaluasi, bertujuan melihat progres dan capaian setiap tahapan program ini agar seluruh program dapat terlaksana sesuai tujuan. Hasil pengabdian menunjukkan peningkatan kemampuan dalam membuat silase menggunakan alat silase terkompartemen pada para peternak.
\end{abstract}

Kata Kunci: Silase, Alat Silase Terkompartemen 


\section{PENDAHULUAN}

Kecamatan

Kadudampit memiliki luas $7.069 \mathrm{Ha}$ yang terdiri atas $1.266 \mathrm{Ha}$ luas sawah dan $5.803 \mathrm{Ha}$ luas tanah darat. Kecamatan tersebut memiliki jumlah penduduk sebesar \pm 54.449 jiwa. Sebagian besar penduduk kecamatan Kadudampit bermata pencaharian sebagai buruh tani, petani pemilik, dan peternak. Mereka bekerja di bidang pertanian, perikanan, peternakan, perkebunan, dan kehutanan. Di bidang peternakan Kecamatan Kadudampit memiliki 8.325 ternak, yang terdiri atas 460 ekor sapi, 245 ekor kerbau, 1.241 ekor kambing, dan 6.379 ekor domba (BPS Sukabumi, 2016). Ternak domba merupakan hewan yang paling banyak dipelihara oleh Masyarakat di Kecamatan Kadudampit. Jumlah ternak tersebut tentu saja memerlukan jumlah pakan yang tidak sedikit. Peternakan yang diusahakan di Kecamatan Kadudampit merupakan upaya untuk meningkatkan penghasilan baik itu penghasilan utama maupun tambahan. Di lain pihak Kecamatan Kadudampit ini memiliki tanah darat dan sawah yang luas sehingga memiliki potensi untuk mengembangkan usaha peternakan yang bersinergi dengan usaha pertanian.

Permasalahan utama yang dihadapi peternak saat ini yaitu peternak masih mengandalkan pakan hijauan langsung yang banyak tersedia di musim hujan, sehingga di saat musim kemarau datang mereka umumnya kesulitan mendapatkan pakan tersebut (Ramdhan, 2016). Selain itu, tidak teraturnya pergantian musim hujan dan kemarau menambah masalah tersendiri bagi para peternak. Peternak belum mampu menyediakan pakan yang bisa selalu tersedia baik di musim hujan maupun saat musim kemarau datang. Berdasarkan hasil wawancara dengan para peternak, informasi tentang adanya teknologi silase sudah diterima oleh mereka, akan tetapi mereka tidak memiliki kemampuan mengimplementasikan pembuatan silase itu sendiri. Mereka juga tidak memiliki pengetahuan merancang alat pembuatan silase yang yang benar-benar efektif dan efisien.

Dari paparan di atas dapat disimpulkan bahwa permasalahan utama peternak adalah ketidakmampuan mereka dalam mengimplementasikan pembuatan pakan silase dan tidak memiliki alat yang tepat untuk membuat silase tersebut. Oleh karena itu, untuk menyelesaikan permasalahan tersebut, maka perlu ada upaya penerapan teknologi tepat guna kepada masyarakat dalam membuat pakan silase yang bersumber dari hijauan. Teknologi tepat guna yang dimaksud adalah Alat Silase Terkompartemen (ASTER) yang desain dan perakitannya disesuaikan dengan kebutuhan peternak di lapangan.

\section{METODE PELAKSANAAN}

Implementasi ASTER sebagai produk teknologi yang pernah dikembangkan pengabdi dalam Hibah IbM sebelumnya, maka diperlukan serangkaian kegiatan dalam Program Penerapan Teknologi Tepat Guna (PPTTG) ini agar ASTER dapat digunakan oleh peternak domba di Wilayah Kadudampit Kabupaten Sukabumi.

Program implementasi ini dimulai dengan pendekatan dan penjajakan program secara intensif dengan pemerintah Kecamatan Kadudampit dan pemerintah desa yang dipilih yaitu Desa Sukamaju dan Desa Cipetir. Pendekatan ini dilakukan agar kegiatan ini bersinergi dengan program-program yang ada di pemerintahan desa khususnya yang berkaitan dengan upaya peningkatan ternak domba di desa yang 
E-ISSN: 2597-8926

bersangkutan. Solusi diarahkan melalui implementasi ASTER sebagai teknologi yang benar-benar dapat dibutuhkan oleh Masyarakat dan dapat menjadi solusi penyediaan pakan yang berkualitas, murah dan mudah

dilaksanakan. Metode pelaksanaan yang ditawarkan untuk mendukung realisasi program ini dilaksanakan melalui beberapa tahap pada tabel 1 berikut ini.

\section{Tabel 1. Tahap Metode Pelaksanaan Kegiatan PPTTG}

\begin{tabular}{|c|c|c|}
\hline TAHAP & KEGIATAN & PENJELASAN \\
\hline 1 & Sosialisasi Kegiatan & $\begin{array}{l}\text { Sosialisasi ini bertujuan untuk memperkuat } \\
\text { pemahaman masyarakat terhadap simpul-simpul } \\
\text { yang menentukan adopsi teknologi }\end{array}$ \\
\hline 2 & Perancangan ASTER & $\begin{array}{l}\text { Tahapan ini terdiri dari rancangan program dan } \\
\text { rancangan alat (ASTER), sehingga } \\
\text { memungkinkan adanya modifikasi dan perbaikan } \\
\text { dari ASTER yang pertama digagas dalam } \\
\text { program IbM Silase bagi Peternak Domba } \\
\text { Takokak tahun 2015. }\end{array}$ \\
\hline 3 & Perakitan ASTER & $\begin{array}{l}\text { Perakitan ASTER dilakukan menggunakan } \\
\text { bahan yang mudah didapat, seperti tong/ silo } \\
\text { bekas industri, dan besi bekas serta tenaga ahli } \\
\text { perakitan yang banyak terdapat di Kabupaten } \\
\text { Sukabumi. }\end{array}$ \\
\hline 4 & Uji Operasi ASTER & $\begin{array}{l}\text { Uji Operasi dilakukan oleh pihak peneliti/ } \\
\text { pengabdi, dan kedua mitra bertujuan untuk } \\
\text { memastikan fungsi dan teknis penggunaan alat } \\
\text { dapat difungsikan oleh mitra dengan hasil silase } \\
\text { yang memenuhi standar minimal silase. Uji } \\
\text { operasi ASTER dipandu menggunakan Lembar } \\
\text { Cek, Lembar Observasi, dan Wawancara yang } \\
\text { mengarah pada efektivitas fungsi alat, } \\
\text { kemudahan penggunaan alat, dan kualitas silase } \\
\text { yang didapatkan. }\end{array}$ \\
\hline 5 & $\begin{array}{l}\text { Pendampingan } \\
\text { Operasional }\end{array}$ & $\begin{array}{l}\text { Berdasarkan hasil uji operasional ASTER, } \\
\text { didapatkan rekomendasi perbaikan, penyesuaian } \\
\text { dan penyempurnaan ASTER yang sesuai dengan } \\
\text { kebutuhan dan harapan dari mitra. Tindaklanjut } \\
\text { dari perbaikan dan penyempurnaan alat dan } \\
\text { prosedur akan disosiasisasikan kembali serta } \\
\text { dilakukan pendampingan kepada mitra agar } \\
\text { mampu mengoperasionalkan ASTER secara } \\
\text { maksimal dan menghasilkan silase yang baik }\end{array}$ \\
\hline 6 & Penerapan ASTER & $\begin{array}{l}\text { Penerapan ASTER dilakukan dengan cara } \\
\text { menghibahkan alat kepada kelompok mitra dan } \\
\text { dijelaskan pula bagaimana mengkontruksi/ } \\
\text { merancang alat tersebut agar mampu } \\
\text { dimanfaatkan, diperbanyak dan dikembangkan } \\
\text { oleh mitra. }\end{array}$ \\
\hline 7 & Monitoring dan Evaluasi & $\begin{array}{l}\text { Monitoring dan evaluasi, bertujuan melihat } \\
\text { kemajuan dan capaian setiap tahapan program ini } \\
\text { agar seluruh program dapat terlaksana sesuai } \\
\text { tujuan. }\end{array}$ \\
\hline
\end{tabular}




\section{HASIL DAN PEMBAHASAN Deskripsi Alat}

ASTER merupakan alat yang berfungsi sebagai reaktor untuk membuat silase. Silase adalah pakan yang telah diawetkan yang diproses dari bahan baku berupa tanaman hijauan, limbah industri pertanian, serta bahan pakan alami lainnya, dengan jumlah kadar/kandungan air pada tingkat tertentu, kemudian dimasukkan dalam sebuah tempat yang tertutup rapat kedap udara yang biasa disebut dengan Silo, selama tiga minggu. Dalam silo tersebut akan terjadi beberapa tahap proses anaerob (proses tanpa udara/oksigen), dimana bakteri asam laktat akan mengkonsumsi zat gula yang terdapat pada bahan baku, sehingga terjadi proses fermentasi (Litbang Pertanian, 2015).

Silase dibuat melalui fermentasi dan dalam kondisi anaerob, maka menjadi suatu ketentuan bahwa pengambilan silase harus dilakukan secara hati-hati, silo harus cepat-cepat ditutup agar udara tidak masuk. Silase paling baik disimpan dalam silo yang berukuran sesuai dengan kebutuhan, sekali ambil isi silo habis (Bolsen et.al 2000). Akan tetapi permasalahan pada tingkat peternak, adakalanya silase diharapkan dapat digunakan beberapa kali. Hal ini terjadi karena kebiasaan peternak membuat silase dalam jumlah yang banyak, namun penggunaannya sedikit demi sedikit. Tidak sedikit akhirnya peternak tidak memperhatikan kualitas silase, karena silo sering dibuka tutup dan berakibat pada kesehatan ternak. Atas dasar permasalah tersebut, kami memodifikasi silo menjadi Alat Silase Terkompartemen (ASTER). Alat ini merupakan modfikasi silo yang memiliki kelebihan sebagai berikut:

a. Memiliki tambahan alat penekan (press), untuk memastikan kondisi silase anaerob atau rendah udara.

b. Silase dibuat dalam silo yang terkompartemen (bagian terpisah), sehingga memungkinkan peternak membuat dan memanen silase dalam waktu yang berbeda.

c. Pembuatan silase bisa dilakukan seorang peternak, karena adanya alat penekan dan pembuatan silase dapat dibuat dalam jumlah sedikit-sedikit (diangsur).

\section{Pelaksanaan Kegiatan}

Program Penerapan Teknologi Tepat Guna (PPTTG) ini dilaksanakan di dua kelompok mitra yaitu kelompok tani dan ternak Nurul Bayan Desa Cipetir dan kelompok tani dan ternak Hegar Manah Desa Sukamaju Kecamatan Kadudampit Kabupaten Sukabumi. Pelaksanaan PPTTG melalui tahapan sebagai berikut.

a. Sosialisasi kegiatan

Tahap ini bertujuan agar pengetahuan dan kesadaran masyarakat pemilik ternak domba menjadi terbuka akan pentingnya pemanfaatan sumber daya hijauan untuk cadangan pakan pada saat musim kemarau. Sosialisasi ini tentunya juga untuk memperkuat pemahaman masyarakat terhadap simpul-simpul yang menentukan adopsi teknologi. Selain itu, dalam sosialisasi ini diberikan pengetahuan tentang pakan silase, sumber-sumber yang dapat dijadikan pakan silase, cara membuat pakan silase dari hijauan, serta manfaat yang dapat diperoleh dari pembuatan pakan silase ini. Kegiatan ini diakhiri dengan penandatangan fakta integritas, sebagai bukti legalitas kesediaan mitra dalam mengikuti program yang dilaksanakan ini. 

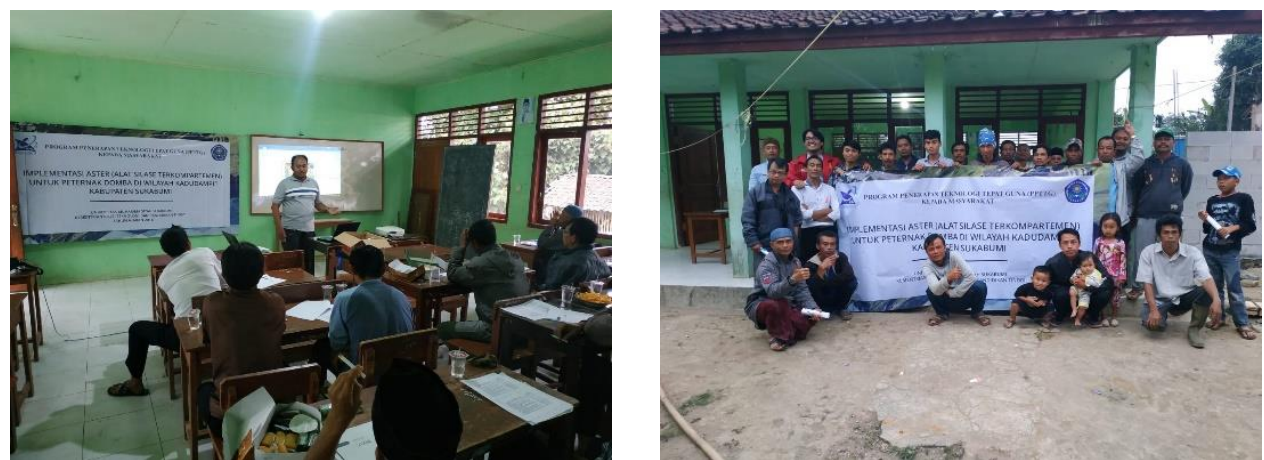

Gambar 1. Kegiatan Sosialisasi dan Pelatihan Teknik Pembuatan Silase

b. Perancangan ASTER

Tahapan ini terdiri dari rancangan program dan rancangan alat (ASTER). Perancangan ini melibatkan beberapa orang mulai dari seorang akademisi (Guru SMK), dan dua orang profesional dalam bidang perangcangan alat dan Welder. Rancangan alat ditargetkan untuk mendapatkan alat yang efektif dan efisien baik dalam perancangan maupun pemanfaatannya nanti oleh peternak. Dalam perancangan ini menghasilkan beberapa catatan penting, antara lain:

1) Penggunaan tong besar yang tidak menyebabkan karat, bisa dari bahan stanless, PVC, tong bekas, atau tong besi berbahan berlapis galvanis.

2) Penggunaan plat besi full yang kokoh

3) Ada sistem kunci pintu yang mampu menekan ke bawah akan tetapi tidak kembali ke atas.

4) Ada sistem rel dalam yang memastikan plat melaju ke bawah dengan rata dan tetap pada rel kunci pintu

5) Ada pengunci plat bawah yang memastikan silase tidak akan jebol
6) Ada pengepres yang stabil menggunakan skrup.

c. Perakitan ASTER

Perakitan ASTER dilakukan menggunakan bahan yang mudah didapat. Setelah dilakukan survey bahan, ditentukan menggunakan tong besi dalam bervolumen 100 liter dengan bahan dalam berlapis galvanis, kaki-kaki menggunakan besi holo $4 \times 2$ berbahan paling tebal, sekat plat besi dengan ketebalan $5 \mathrm{~mm}$, skrup drat diameter $2 \mathrm{~cm}$ dengan panjang 1 meter.

d. Uji operasi ASTER

Uji Operasi dilakukan oleh pihak pengabdi, di bengkel rekanan yang mendapatkan pekerjaan dengan menggunakan sistem kedap air. Karena dalam sistem silase yang mengharuskan sistem kedap udara/ anaerob. Pengujian ini memasukan air ke dalam wadah dan menekan air dalam sekat, diujikan daalamm waktu 3 hari, dan tidak ada terjadi kebocoran. Uji kedua menggunakan campuran silase yang akan siap di peram, proses ini dilakukan selama tiga tahap selama tiga hari. Satu sekat plat diisi oleh bahan silase, lalu hari kedua dimassukan bahan silase 
berikutnya saampai hari ke tiga. Setelah satu minggu dilakukkan pengnecekann dan hasil silase menunjukkan karakteristik silase yang baik, yaitu warna hijau kekuningan dan bearoma harum. Tahapan ini sebagaimana dipaparkan pada tahap metode bertujuan untuk didapatkannya ASTER yang sesuai dengan kebutuhan mitra.

e. Pendampingan Operasional Sebelum ASTER digunakan, kedua mitra mendapatkan pelatihan terlebih dahulu. Materi pelatihan berisi tentang teknologi pembuatan silase dan pengenalan Alat ASTER yang bertujuan untuk: (1) memberikan pemahaman, pegetahuan, dan keterampilan kepada masyarakat mengenai teknik pembuatan pakan silase dari hijauan; (2) menerapkan landasan-landasan untuk mengubah kebiasaan masyarakat mencari hijauan hanya untuk hari ini menjadi berpikir untuk hari esok, di saat musim kemarau datang; (3) menggunakan ASTER untuk menghasilkan silase berkualitas. Penyerahan alat dilakukan kepada peternak dengan sistem satu alat oleh satu kelompok sebagai bagian dari pembelajaran bersama. Pendampingan penggunaan alat dan perawatan ini ini dilakukan secara berkala, baik secara langsung ke lokasi petani maupun lewat komunikasi menggunakan sosial media. Dari beberapa proses pendampingan didapatkan beberapa masalah diantaranya:

1) Beberapa peternak masih bingung tata cara penggunaan alat karena belum dilengkapi manual atau petunjuk bagian dan fungsi setiap alatnya.
2) Mekanisme pengepresan kurang efisien, membutuhkan waktu dan menyulitkan petani.

3) Pegangan pada plat sekat kompartemen belum ada, menyulitkan peternak dalam memasukan plat kompartemen.

4) Alat pembuka sekat dasar masih membutuhkan kunci pas, harusnya pakai handle yang praktis.

Dari temuan ini pengabdi berupaya menyempurnakan alat ASTER dengan cara melengkapi manual, memperbaiki mekanisme pengepresan, membuat pegangan pada plat sekat kompartemen, dan membuat handle praktis buat alat pembuka sekat dasar.

f. Penerapan ASTER

Penerapan ASTER dilakukan dengan cara menghibahkan alat kepada setiap peternak setelah dilakukan perbaikan dari purwarupa yang telah peternak pelajari dari tahap pendampingan operasional.

g. Monitoring dan Evaluasi, Monitoring dan evaluasi merupakan kegiatan untuk menilai tingkat keberhasilan dan keberlanjutan kegiatan pengabdian kepada Masyarakat ini. Tahapan monitoring dan evaluasi yang dilaksanakan antara lain:

1) Monitoring dan mengevaluasi kader peserta sosialisasi dan pelatihan, yaitu meliputi kegiatan wawancara guna mengetahui motivasi peserta dan pengetahuan dasar tentang silase.

2) Monitoring dan mengevaluasi persiapan kegiatan sosialisasi dan pelatihan, yaitu meliputi pengecekan tempat pelatihan, kelengkapan alat dan bahan pada saat kegiatan, dan penyediaan makalah/bahan 
pelatihan yang akan disampaikan.

3) Monitoring dan mengevaluasi saat pelatihan berlangsung, yaitu meliputi pengecekan kehadiran peserta dan memberi motivasi agar kegiatan ini dapat diikuti dengan baik.

4) Monitoring dan mengevaluasi hasil/produk pasca pelatihan,

yaitu menilai hasil kerja peserta dalam bentuk komentar yang bersifat membangun.

5) Monitoring dan mengevaluasi kemampuan mitra dalam menggunakan dan menyelesaikan masalah dalam penggunaan ASTER.
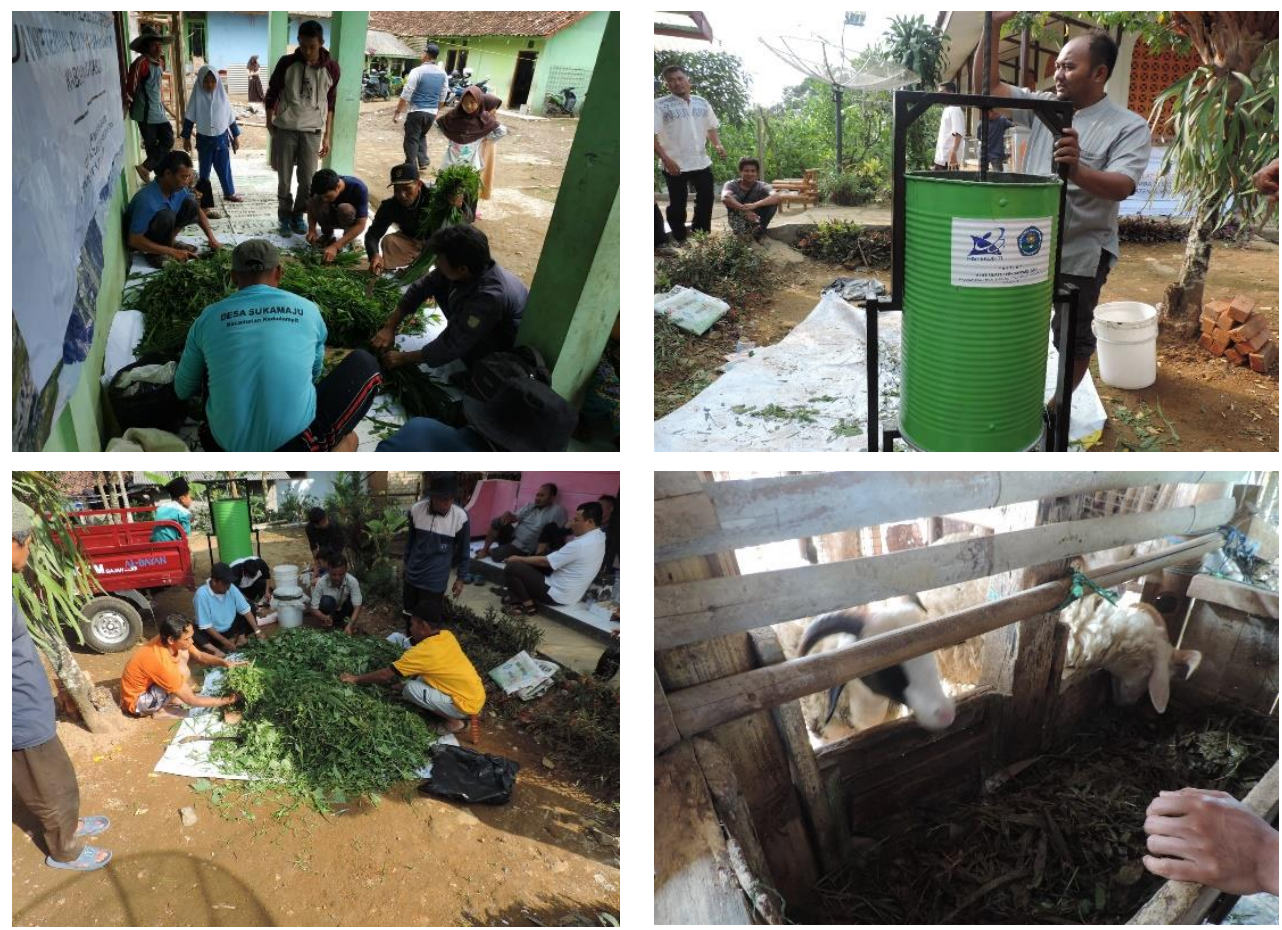

Gambar 2. Pembuatan Silase Menggunakan Alat Silase Terkompartemen

\section{Hasil}

Secara umum pelaksanaan kegiatan PPTTG dalam bentuk pelatihan pembuatan silase dan implementasi ASTER kepada peternak domba sudah dilaksanakan sesuai program dan mencapai keberhasilan yang dapat dilihat dari pencapaian indikator yang telah ditetapkan. Beberapa pencapaian yang telah dapat antara lain:

a. Adanya dukungan dari pemerintah setempat untuk memfasilitasi kegiatan ini, ditunjukkan dengan keluarnya surat ijin melaksanakan kegiatan PPTTG serta bantuan fasilitas dari pemerintah setempat.

b. Keterlibatan masyarakat untuk ikut serta dalam kegiatan ini dengan jumlah peserta 20-25 orang dari dua kelompok mitra.

c. Meningkatnya pemahaman peserta dalam mengikuti sosialisasi, dan pelatihan membuat silase dengan rata-rata skor pretest sebesar 46,7 dan meningkat menjadi 71,4 pada rata-rata skor postest.

d. Suksesnya pelaksanaan sosialisasi dan pelatihan yang ditunjukkan dari hasil angket evaluasi pelaksanaan, antara lain: 
E-ISSN: 2597-8926

pelaksanaan pelatihan dinilai 81,43, kualitas pembicara/ narasumber 82,29 , dan lain-lain (konsumsi, tempat) dinilai 85,71

serta beberapa masukan dan saran yang intinya kegiatan ini sangat tepat, bermanfaat, dan harus terus dijaga keberlanjutannya.

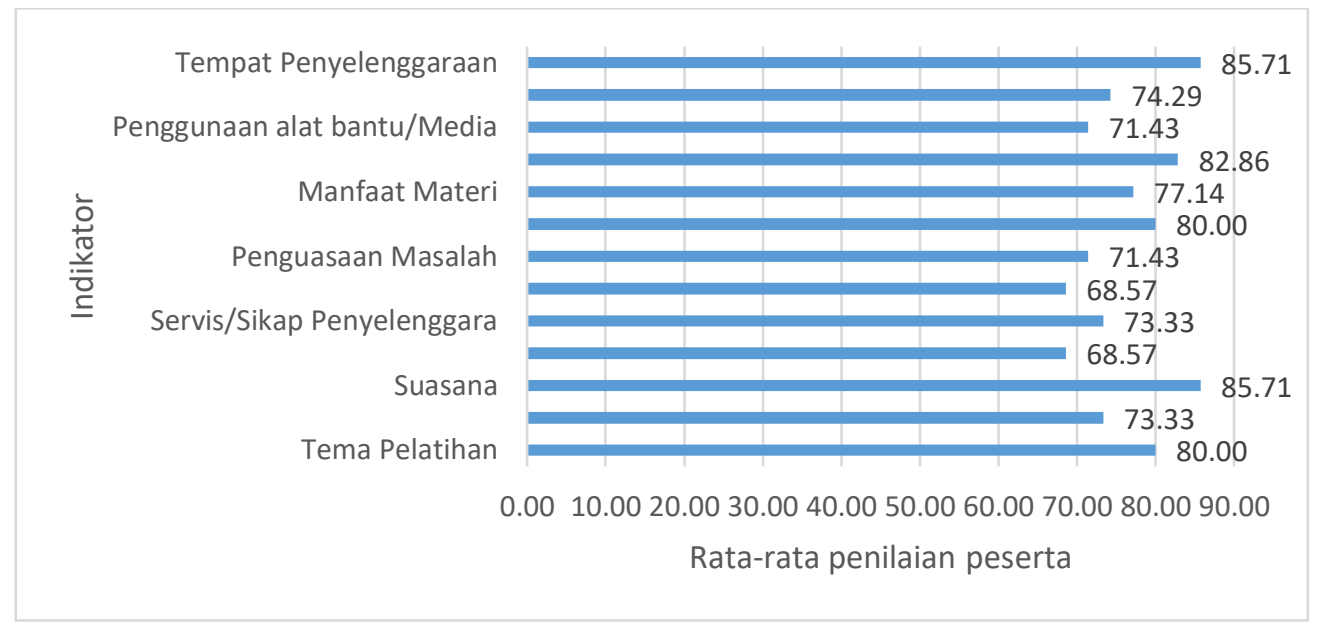

Gambar 3 Grafik Hasil Evaluasi Pelaksanaan Sosialiasi dan Pelatihan

e. Hasil monitoring dan evaluasi menunjukkan adanya peningkatan kemampuan para peternak dalam membuat silase menggunakan alat silase terkompartemen. Angka keberhasilan dalam membuat
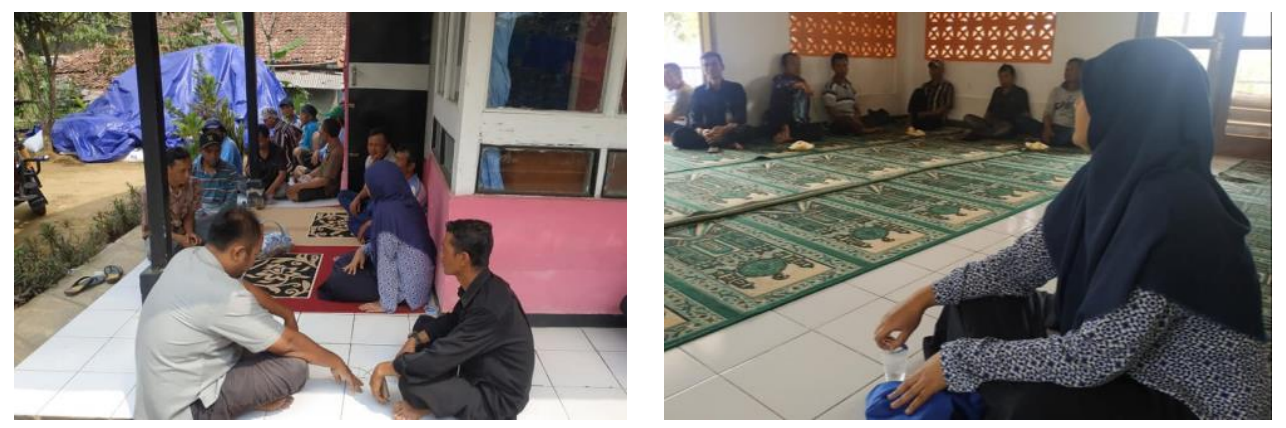

silase mencapai 95\%. Selain itu, Peternak sudah mampu menanggulangi kendalakendala yang dihadapinya terutama dalam penyediaan pakan saat musim kemarau.

Gambar 4. Kegiatan Monitoring dan Evaluasi Implementasi Alat Silase Terkompartemen

\section{PENUTUP}

Kegiatan beternak domba pada masyarakat Desa Cipetir dan Desa Sukamaju merupakan tumpuan hidup, sehingga apapun teknologi atau pengetahuan tentang pengembangan teknik beternak domba menjadi hal yang prioritas bagi masyarakatnya. Hasil pengabdian menunjukkan adanya peningkatan kemampuan para peternak dalam membuat silase menggunakan alat silase terkompartemen. Teknologi silase mampu menjawab kesulitan peternak domba akan ketiadaan pakan ketika menghadapi musim kemarau. Teknologi tepat guna Alat Silase Terkompartemen (ASTER) sangat mudah dirakit dan digunakan oleh masyarakat untuk menghasilkan silase yang berkualitas tanpa menurunkan 
E-ISSN: 2597-8926

kualitas silase pada saat bongkar muat silase. Rekomendasi untuk kegiatan selanjutnya adalah sosialisasi, pelatihan silase, dan implementasi ASTER harus dikembangkan dalam skala lebih besar dengan melibatkan lebih banyak lagi peserta. Pendampingan harus melibatkan kader dari Desa Cipetir dan Desa Sukamaju yang telah mendapatkan teknologi tepat guna ASTER untuk pembuatan silase. Dengan pertimbangan di Kecamatan Kadudampit masih terdapat tujuh desa lainnya sebagai penghasil domba, selain Desa Cipetir dan Desa Sukamaju. Sehingga Teknologi Tepat Guna ASTER dapat memberikan dampak yang lebih luas.

\section{DAFTAR PUSTAKA}

Abbas SA, Halim ST, Amir D. 1985. Limbah Tanaman Padi dalam Limbah Hasil Pertanian. Jakarta: Kantor Mentri Muda Urusan Peningkatan Produksi Pangan.

Astuti P, Sukarni S. 2004. Kinerja Domba Lokal yang Mendapatkan Limbah Padat (Blotong ) Industri Pabrik Gula. Karanganyar: APEKA.

BPS Sukabumi. 2016. Kabupaten
Sukabumi dalam Angka 2016. Sukabumi: BPS Sukabumi

Chuzaemi S, Soejono M. 1987. Pengaruh Urea Amoniasi terhadap Komposisi Kimia dan Nilai Gizi Jerami Padi untuk Sapi Peranakan Ongole. Didalam: Proceedings Bio Conversion Project Second Workshop Crop Residues for Feed and other Purposes. Grati, 16-17 Nov 1987. hlm6873.

Parakkasi A.1995. Ilmu Nutrisi dan Makanan Ternak Ruminan. Jakarta: UI Pr.

Ramdhan B., Suhendar, Astutiningsih E.T. 2016. Ketahanan Pakan Melalui Silase Untuk Ternak Domba Di Kecamatan Takokak, Kabupaten Cianjur. Agro Kreatif Jurnal Pengabdian Kepada Masyarkat. Vol 2 (1): 39-46

Hidayat M, Harjono, Marsudi, Gunanto A. 2006. Evaluasi Kinerja Teknik Mesin Pencacah Hijauan Pakan Ternak. Jurnal Enjiniring Pertanian. 4(2): 61-64. 